\title{
Defining the Integrated Performance Measurement Systems in Small and Medium Enterprises: An Advanced Model
}

\author{
Pirozzi Maria Grazia ${ }^{1}$, Agliata Francesco ${ }^{2}$, Tuccillo Danilo ${ }^{3} \&$ Pirozzi Francesco $^{4}$ \\ ${ }^{1}$ Phd in Economics and Management of Healthcare Organizations and Enterprises, Department of the Teaching \\ Hospital Trust, University of Naples "Federico II", Italy \\ 2 Associate Professor of Accounting, Department of Economics, Corso Gran Priorato di Malta, University of \\ Campania “Luigi Vanvitelli”, Italy \\ ${ }^{3}$ Associate Professor of Accounting, Department of Economics, University of Campania "Luigi Vanvitelli”, Italy \\ ${ }^{4}$ Business Analyst, E.M.M. Informatica S.r.l., Inail Polyfunctional Center, Naples, Italy \\ Correspondence: Agliata Francesco, Associate Professor of Accounting, Department of Economics, Corso Gran \\ Priorato di Malta, University of Campania “Luigi Vanvitelli”, Italy. E-mail: f.agliata@unina.it
}

Received: November 10, 2019

Accepted: November 22, 2019

Online Published: November 27, 2019

doi:10.5539/ijbm.v14n12p203

URL: https://doi.org/10.5539/ijbm.v14n12p203

\begin{abstract}
Purpose: The purpose of this paper is to propose an "Integrated Performance Measurement System" (PMS) addressing the measurement and management of the financial and non-financial performance and "Intellectual Capital" (IC) for the "Small and Medium Entreprises" (SMEs). The paper relies on the "Integrated New Model" (INM) by Pirozzi and Ferulano (2016) that deals with the same task applied to a specific sector. Thus, we propose the modification of the INM model to define a "Renewed and Advanced Model" called "INM*" as integrated PMS for SMEs.

Design/methodology approach: We used a qualitative method with an inductive and deductive approach to obtain an advanced model INM*. Thus, the SMEs characteristics are translated in our advanced INM* model according to the INM* structure and the IC framework. Moreover, we integrated in our proposed model INM* the "Strategic Management Accounting" (SMA) and the "Systems of Innovation" (SI) perspectives.
\end{abstract}

Findings: We proposed the advanced model INM* as integrated PMS. This is a model supporting entrepreneurial and innovative SME as well as a conceptual framework summarizing the interactions and the knowledge conversions that occur between the IC components within the innovation processes. Thus, the proposed model is a useful tool for SMEs organizations.

Originality/value: The renewed and advanced model INM* is useful in the academic and practical communities. It exhibits the advantages related to the innovative usage of a unique measurement system devoted to accomplish all the measurement tasks activated by SMEs. In addition, two other models are proposed and, in turn, are available for further research.

Keywords: integrated performance management system (PMS), intellectual capital (IC), strategic management accounting (SMA), small and medium enterprises (SMEs), systems of innovation (SI), integrated new model (INM), renewed and advanced model (INM*)

\section{Introduction}

The small and medium sized enterprises (SMEs) represent the most diffused type of private and productive organizations contributing the market economy in several countries. The European Commission (2015 and 2017) stated that SMEs are the enterprises "which employ fewer than 250 persons and which have an annual turnover not exceeding EUR 50 million, and/or an annual balance sheet total not exceeding EUR 43 million”. Additionally, it is noteworthy that "nine out of every 10 enterprises is an SME, and SMEs generate two out of every three jobs" (European Commission, 2015; 2017). Thus, several Scholars investigate SMEs under several perspectives (e.g. management, accounting, organizational, planning and control, assessment) to define models and methods for their survival in the long term (Castela et al., 2018; Massaro et al., 2016; Abdulsaleh et al., 2013). Particularly, the SMEs' management needs to be supported by adequate performance measurement 
system (PMS) to compete in the market emphasizing also strategic intangible assets (or intellectual capital) as items contributing the achievement of high performance and value creation (Dumay \& Guthrie, 2015; Firer \& Stainbank, 2003; Guthrie et al., 2017; Secundo et al., 2018).

In this perspective, SMEs' characteristics have to be identified to adopt an adequate PMS (Adair et al., 2006; Davis and Albright, 2004; Nielsen, 2019; van der Merwe and Visser, 2008). Jennings and Beaver (1997) identifies SME's peculiarities in the structural and managerial aspects of the coordination process, and in the specificities of the risk-taking, innovation and of the interfaces toward the market. Indeed, the limited structural complexity of a SME allows for a higher flexibility, meanwhile the managerial process is personalized because it depends by the presence of a restricted management group that is also the SME's owner (so called “owner-manager"). Additionally, the SME' configuration requires a specific risks' analysis deriving from the environment's uncertainty and in this way the innovation process results more easy to trigger and to bring it to successful conclusion. Thus, the SME management is often meant to be entrepreneurship-driven.

The purpose of this paper is the proposition of the PMS based on both financial and non-financial performance and the IC measurements of SME organization. The paper relies on the Integrated New Model (INM) by Pirozzi and Ferulano (2016) that deals with the same task applied to a specific sector (healthcare organizations). The INM model by Pirozzi and Ferulano (2016) is obtained assuming three generalized models (CAF, EFQM and Malcolm Baldrige) requiring for a specific customization in relation to characteristics of target organizations (European CAF Resources Centre, 2006). Thus, according to the SMEs definition (European Commission, 2015; 2017), we retain the SMEs sector a real pivotal components of economic production systems in several countries, requiring an adequate PMS. In this perspective, our paper proposes an advanced model composed of 43 sub-criteria directed to SMEs assuming the Pirozzi and Ferulano (2016) model composed of 19 sub-criteria.

Thus, we propose the modification of the INM model to propose a renewed and advanced model of SMEs called "INM*" as integrated PMS, including also multidimensional elements (e.g. organizational culture and climate, entrepreneurship intensity and the four knowledge components that support the innovation process). Additionally, a strategic perspective is adopted considering also the strategic management accounting (SMA) process, including specific sub-criteria in the advanced model INM*. The macro-processes underlying the entrepreneurial activity and the innovation are considered, taking also into account the external environment affecting the SME organization adopting the System of Innovation (SI) (Freeman, 1995).

Within this paper a more deep analysis of the internal nature of the IC components was also performed, whereby some specific conceptual constructs (e.g. organization climate and culture, ambidexterity and the entrepreneurial intensity) were included as components of the structural capital. Furthermore, specific sub-criteria of our INM* model were included in the final model describing the innovation capability residing in the SME organization. Finally, this paper also detected the interactions between different knowledge components (embodied, embrained, embedded, encoded) and their allocation among the IC components (human, structural, relational).

Therefore, the effort provided by our advanced INM* model produces new insights as far as it concerns the complementarity property and the dynamic dimension of the IC components. In this way, existing literature emphasizes the lack of studies on PMS and IC and SME sector as well as the lack of SMA literature in the same direction. Thus, the overcoming lacks in the literature allow us to propose to academic and practical communities the SMEs as target sector supporting the advanced model. In the Figure 1 is outlined the logical flow of this paper. 


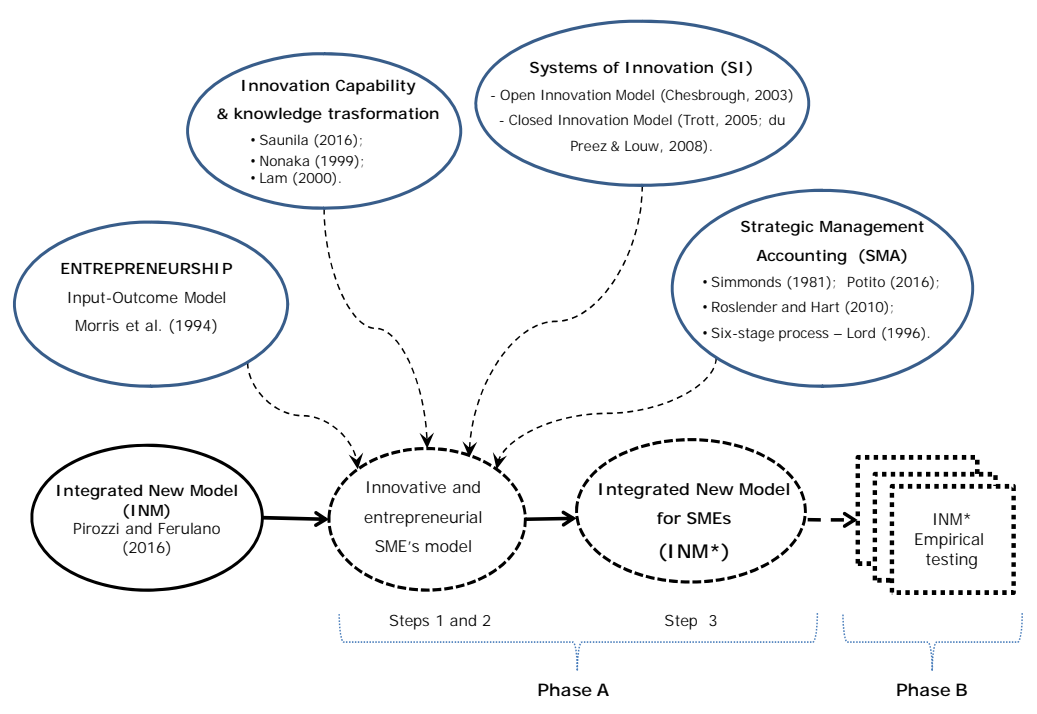

Figure 1. Research logical flow

The remainder of the paper is organised as follows: Section 2 examines relevant literature. Section 3 presents the research methodology. Section 4 presents the findings and discussion. Lastly, Section 5 presents conclusions of the paper, limitations and future research.

\section{Literature Review}

The performance measurement systems (PMS) facilitate the corporate strategies implementation and the improvement of organizational performance (Adair et al., 20016; Davis and Albright, 2004; Nielsen, 2019; van der Merwe and Visser, 2008). The internal management and reporting systems are tailored to offer a more holistic representation of the firm (Lev and Daum, 2003) to "provide stakeholders and managers with a comprehensive evaluation system of value creation, of the various factors of production, assets, processes and procedures, and their different combinations" (Pirozzi and Ferulano, 2016). Ittner et al. (2013) sustain that there is the need to integrate the PMS with other measurement systems in the organization context, pointing out that scant attention was paid so far to pursue this scope. Despite the wide efforts spent by scholars to assess PMS requirements and their practical application in large organizations there is still a scarce production of research results for SME (Hudson et al., 2000).

Among the most diffused measurement frameworks, the European Foundation for Quality Management or EFQM's Business Excellence Model is included (EFQM, 2013; Nabitz et al., 2000; Shaw, 2000). It consists of two different sub-sections of parameters: i) enablers and, ii) results. Assuming the EFQM model, enablers factors are items that managers can trigger in order to obtain the desired results. The INM proposed by (Pirozzi and Ferulano (2016) is based on Common Assessment Framework (CAF) that derives from the EFQM model. This latter provides a loose definition of enabling/results parameters that make it flexible enough to fit different organizations in different sectors. Considering the wide range of SMEs' characteristics, the peculiarity of EFQM seems particularly useful to address the research proposed in this paper.

Our paper offers a viable solution to bridge this gap proposing a unique PMS that is able to face the challenge to measure and manage the traditional performance parameters, with those financial and non-financial, and Intellectual Capital (IC). The relationship between IC and the creation, running and continuous adaptation of entreprises strategy to the internal and external changes to achieve superior performance and strategic performance measurement, is clearly asserted (Marr and Roos, 2005; Klaila and Hall, 2000; Carrel, 2007; Roos et al., 2001).

The resources-based view (RBV) of firm stated that organizations create competitive advantages by leveraging the internal resources that are difficult to replicate by other firms (Wernerfelt, 1984; Rumelt, 1984; Barney, 1991; Hall, 1993; Lev, 2003). The IC based view of firm represents a narrow perspective of more general RBV, so that the property of "complementarity", owned by RBV, is also active in IC framework (Ling, 2012). Kogut and Zander (1992) pointed out that "firms are a repository of capabilities", also suggesting that "firms learn new skills by recombining their current capabilities". Grant (1991) maintained that "a capability is in essence a 
routine, or a number of interacting routines. The organization itself is a huge network of routines". Bontis (1999), noted that IC is a multidimensional second-order conceptual construct (Kogut and Zander, 1992), divided into three sub-domains: human capital, structural capital and relational capital.

In this scenario, human capital is the "tacit knowledge" (Polanyi, 1967) embedded in the minds of working people; the structural capital consists of organizational routines (Nelson and Winter, 1982; Grant, 1991) of business and, finally, the relational capital is formed by the knowledge embedded in the relationships with external environment. This IC definition is assumed as basic reference by this work. Despite the general consensus on the strategic relevance of IC in organizations (Dumay and Garanina, 2013; Dumay and Guthrie, 2015; Secundo et al., 2018), a gap between IC theoretical findings and the practical implementation still exists (Carrell, 2007, 2010). Moreover, scant attention to analysis of IC in SMEs was devoted so far (Guthrie et al., 2012; Guthrie et al., 2017; Marzo and Scarpino, 2016). According to Nixon and Burns (2012), the "more internal and resources based view of organizations and competitive advantages" approach to strategic management (SM) is almost neglected in SMA literature. This paper addresses these solicitations by means the pursuing of "managerial significance" (Becker and Huselid, 2006; Bazerman, 2005) of IC research (Pirozzi and Ferulano, 2016), and the integration of SMA process (Lord, 1996) in INM* model.

In the next sub-sections, we define the theoretical characteristics of SMA and its relationship with IC, the connections between structural capital and organizational routines, the INM framework, entrepreneurship, innovation process, innovation capability and the open and closed SI. We retain following sub-sections functional to the SME model's definition whereby a set of enablers factors will be inferred and integrated in the advanced model INM*.

\subsection{The Integrated New Model (INM)}

The Integrated New Model by Pirozzi and Ferulano (2016) addresses IC and financial and non-financial performance measurement in healthcare organizations. This model was produced by integrating Common Assessment Framework (CAF) model with two other frameworks: i) the IC by Health Agency of Emilia-Romagna Region (Italy) (Baccarini et al., 2008) and, ii) the Leadership by UK National Healthcare System (NHS) (Storey and Holti, 2013). The integration phase was operated by comparing the CAF and IC models to assess the determinant factors supporting both frameworks and eliminating such redundancies.

Concerning the leadership determinant factor, the relevant conceptual framework of CAF model was changed by new leadership model proposed by NHS and specifically devoted to healthcare organizations. The INM model by Pirozzi and Ferulano (2016) is composed of six enablers factors and four results factors. This model includes also a feedback loop that addresses the continuous reengineering of the model itself required by strategy change/adaptation over the time. The similarity of INM model with CAF model, EFQM and Baldridge models, makes the INM model applicable to a wide range of public and private organizations.

\subsection{The Strategic Management Accounting (SMA)}

The alignment of the corporate strategy with the management accounting is not an easy task for managers and consultants. The crossing of these two research streams gave rise to a new framework of study named strategic management accounting (SMA) that still misses of a widely accepted definition (Langfield-Smith, 2008). Simmonds (1981) defined SMA as "a form of management accounting in which emphasis is placed on information which relates to factors external to the firm, as well as non-financial information, and internally generated information".

The SMA theoretical concept and its practical application were shaped according to the evolution of theoretical basis on which the different approaches to strategy were proposed over the time. Basically, four main perspectives to strategy emerged along the last fifth years (Whittington, 2001; Nixon and Burns, 2012) aka Classical, Evolutionary, Processual and Systemic, each one conceived considering the shareholders-stakeholders orientation of the delivery of wealth generated by enterprise's activities and the deliberate-emergent character of strategy (Mintzberg, 1978). In the late '70 a new approach to SM emerged connoted by a "more internal, resources based view of organizations and competitive advantages". This latter approach gave rise to the so-called "second era of SM" (Herrmann, 2005). Nixon and Burns (2012) pointed out that this new approach to SM "has been mostly neglected by the extant SMA literature".

The integrated PMSs adopting financial-non financial measurement are comprised among the SMA techniques (Guilding et. al., 2000; Cinquini and Tenucci, 2007; Cadez and Guilding, 2008; Pratono, 2016). According to Roslender and Hart (2010), the SMA constituent components are strategy, management and accounting, so that SMA is identifiable as "the provision of (managerial) accounting information in support of strategic management 
process". Lord (1996) identified SMA as a six-stage process: (1) collection of competitor information, (2) exploitation of cost reduction opportunities, (3) matching of accounting emphasis with strategic position, (4) collection of competitor information, (5) exploitation of cost reduction opportunities, and (6) matching of accounting emphasis with strategic position.

\subsection{The International Financial Reporting Standard ${ }^{\circledR}$ (IFRS $\left.{ }^{\circledR}\right)$ for SMEs}

According to the international rules and standards regulating the accounting of enterprises, a set of parameters should be further included in " 10 . Results for Key performance" criterion, in order to highlight the SME financial position. The International Accounting Standards Board (IASB) develops and issues a separate International Financial Reporting Standard ${ }^{\circledR}$ (IFRS ${ }^{\circledR}$ ), intended to apply to the general purpose financial statements for small and medium-sized entities (SMEs), private entities and non-publicly accountable entities (Newberry and Ram, 2013). The IFRS for SMEs (IASB, 2015) is based on full IFRS with modifications to reflect the users' needs of SMEs financial statements and cost-benefit considerations (IASB, 2015; Potito, 2016). The financial statements included into INM* criteria "Results for Key Performance" are the following: statement of financial position, income statement and a statement of comprehensive income, statement of changes in equity; statement of cash flows (IASB, 2015).

\subsection{The Structural Capital and the Organizational Routines}

The structural capital is a relevant component of the intellectual capital (IC). The IC investigation appears as relevant to define several issues among which its influence on the organization performance (Dumay and Guthrie, 2015; Firer and Stainbank, 2003; Guthrie et al., 2017; Secundo et al., 2018). The sudy by Dumay (2016) propose the IC definition as " ... the sum of everything everybody in a company knows that gives it a competitive edge ... Intellectual Capital is intellectual material, knowledge, experience, intellectual property, information... that can be put to use to create value". Particulart, the structural capital is made up by organizational routines (Bontis, 1999; Dumay and Garanina, 2013; Firer and Stainbank, 2003) as basic components of organizational behaviour and repositories of organizational capabilities (Becker et al., 2005; Nelson \& Winter, 1982; Stewart, 1998).

In this way, the terms organizational routines or routines reflects actions by organizations. The creation of the organization's capabilities implies a "complex patterns of coordination between people and between people and other resources" (Grant, 1991). Indeed, Nelson and Winter $(1977,1982)$ stated that "the organizational routines are regular and predictable patterns of activity which are made up of a sequence of coordinated actions by individuals".

\subsection{Stability, Change and Ambidexterity}

Becker (2004) stated that "to the extent that routines recur without change, they provide stability" (Hodgson, 1993; Nelson, 1994; Langlois, 1992). Nevertheless, sometimes the tendency to the stability becomes "pathological", viz a routine persists despite it produced negative performance, giving rise to an organizational inertia. However, the capability to change remains embedded in the nature of the routines so that they are not inert, but normally they change over the time, contributing to the stability, the change and the flexibility of an organization (Becker, 2004).

This work suggests that the structural capital, being formed by a huge network of organizational routines, actually realizes a compromise between the organizational and the market agilities (Wright et al., 1999) and the structural inertia (Hannan and Freeman, 1977, 1984). Indeed, the continuous research for the dynamic balance between change and conservation seems necessary to preserve the organization's life and its well being (Lawrence and Lorsch, 1967). This dynamic balancing is defined as the organization's "ambidexterity" (Tushman and O'Reilly, 1996, 1999), indicating with this term the organization's capability to lead both evolutive/adaptive and revolutionary changes.

Subramaniam and Youndt (2005) pointed out that the social and the organizational capitals positively influence both incremental and radical innovative capabilities pointing out the relationship between IC components and the "ambidextrous" character of organizations. Therefore, this work assumes that ambidexterity is an important systemic characteristic of organization, realized through a set of routines, so that it resides within the structural capital.

\subsection{Trigger Mechanism}

An organizational routine is activated by a set of trigger mechanisms, that can be "actor-related" or provided by an external cues (Becker, 2004), for instance by another routine. This work considers this characteristic in order to highlight both the coordination task of the entrepreneurship process and the integration of the latter with the possible starting and the concurrent running of the innovation capability (Rodriguez Ferradas et al., 2017). 


\subsection{Storing Knowledge}

Nelson and Winter (1982) stated that "the routinisation of activity in an organization is the most important form of storage of the organization's specific operational knowledge". Becker (2004) explained that routines are able to store the "individual-held-knowledge", as well as the "collectively-held-knowledge", and that the concept of routines "is helpful for understanding how the productive knowledge (in particular tacit knowledge) is stored, applied, decays and changes". Nonaka (1994) sustained that a continuous conversion process is active between the tacit and the explicit knowledge, indicating four different types of conversion (socialization, externalization, internalization, combination), stating that "the innovation is a key form of organizational knowledge creation" and that "the organization creates and defines problems and then actively develops new knowledge to solve them". These conversion processes act at different levels (individual, group, organization, inter-organization). The socialization/combination interactions happen inside the firm's boundary, while the externalization/internalization interactions take place between the firm's organization and the external environment.

Considering two different dimensions of knowledge, namely the epistemological distinction between Individual vs. Collective knowledge and the ontological dual nature of knowledge (Tacit vs. Explicit), four different kinds of knowledge are defined: embrained, embodied, encoded and embedded (Lam, 2000; Collins, 1993; Blackler, 1995; Liao and Barnes, 2015).

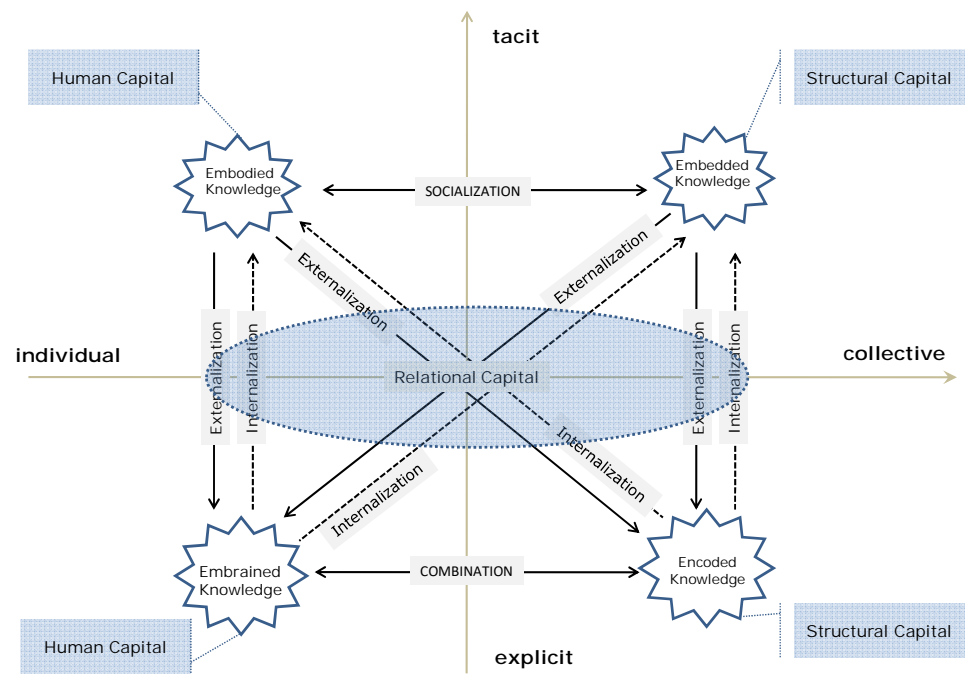

Figure 2. Knowledge components transformation and IC

Source: Our elaboration from Nonaka (1994) and Lam (2000).

The four knowledge components (Lam, 2000) and the conversion processes dynamic (Nonaka, 1994) are mapped with the IC framework so that the interactions that occur between the IC components in the framework of the innovation process, finally, are assessed as depicted in the Figure 2.

\subsection{Entrepreneurship}

The entrepreneurship is an emerging research field (Busenitz et al., 2003; Shane and Venkataraman, 2000) connoted by the lack of a well defined theoretical framework (Wiseman and Skilton, 1999). Nevertheless, Businetz et al. (2003) sustained that the entrepreneurship has the great advantage to offer a comprehensive view of the organizational phenomena underlying the firm, sustaining the legitimacy of the entrepreneurship as research field, as well as its belonging to the management theory. Morris et al. (1994), building up on the findings of Low and McMillan (1988) and Gartner (1990), concluded that (a) the entrepreneurship research should focus on the process underlying the entrepreneurship and the context in which it evolves, rather than the entrepreneur, despite the essential role covered by the latter; (b) the processual nature of the entrepreneurship calls for the distinction between the factors that are inputs and those that are outcomes of the whole process. These authors sustained that the variable nature of entrepreneurship is determined by the behavioural and 
attitudinal components. The first are related to the willingness to face new opportunities and assuming the responsibility to enact the necessary initiatives/changes. The attitudinal components are represented by the capabilities to identify an opportunity, to transform it into a business idea, allocate the necessary resources and, finally, to accept the risks and to operate. The components, behavioural and attitudinal, are considered both at the individual and organizational level. These components explicate their actions along three key dimensions: innovativeness, risk taking and proactiveness (Morris et al., 1994).

\subsection{Innovation Process and Innovation Capability}

The entreprises are subjected to a continuous differentiation process deriving by different capabilities to innovate (Nelson and Winter, 1982). West (1990) argues that innovation is "the intentional introduction and application within a role, group or organization of ideas, processes, products or procedures, new to the relevant unit of adoption, designed to significantly benefit the individual, the group, the organization or wider society". Scholar adopts such definition (Anderson, 2004) since it captures three fundamental aspects of the innovation: the novelty, the application stage and the expected benefits (Lansisalmi et al., 2006). Lazonick (2013) maintained that in order to lead the "uncertain, collective and cumulative" characteristics of the innovation process, three social conditions should be satisfied: the strategic control, the organization integration and the financial commitment (Lazonick and O'Sullivan, 1998; O'Sullivan, 2000).

Moreover, the successful implementation of the innovation initiatives requires a rigorous management of the innovation process (du Preez and Louw, 2008; Jaruzelski et al., 2006). According to Pavitt (2003), the innovation process can be considered articulated in three different sub-processes: (1) research and technological knowledge production, (2) transformation of the knowledge in products, systems, processes and services and (3) continuously searching for the correspondence between these artefacts produced and the need and demands for goods/services expressed by the markets. According to Saunila (2016), the innovation capability represents the potential or the ability to produce innovations (Neely et al., 2001). Furthermore, it is an internal feature that connotes the organization (Martinez-Romàn, 2011), that requires a continuous improvement (Olsson et al., 2010), and finally it is value adding oriented (Hogan et al., 2011).

\subsection{Open and Closed Systems of Innovation (SI)}

The Schumpeterian approach to the innovation (Schumpeter, 1934), together with the Nelson and Winter (1982) theory, gave rise to the study of the innovation under a systemic perspective that is the so-called systems of innovation theory (SI). A SI is defined as "the network of institutions in the public and private sectors whose activities and interactions initiate, import, modify, and diffuse new technologies" (Freeman, 1995), or "the elements and relationships which interact in the production, diffusion and use of new, and economically useful, knowledge" (Lundvall, 1992). Mazzucato (2014) explained that "the emphasis here is not on the stock of R\&D but on the circulation of knowledge and its diffusion throughout the economy", so that the "Institutional change is not assessed through criteria based on static allocative efficiency, but rather on how it promotes the technological and structural change". Edquist (2001) defined a SI as "all important economic, social, political, organizational, and other factors that influence the development, diffusion, and use of innovations."

Therefore, the SI approach is related about the determinants of innovations, not about their consequences. According to Rothwell (1994), the SIs evolved over the time in five successive generations of models. The fifth generation, also named "closed innovation models" (Docherty, 2006), is represented by a class of models based on a systemic and distributed approach (System integration and Networking), characterized by the metaphor of the "funnel", that accounts for the progressive selection of the ideas generated within the organization along the time, and moreover, the so-called "fuzzy front-end". The latter represents the unstructured and confused communication interface throughout which the information and data inflow, from the external environment to the firm's organization, takes place (Trott, 2005; du Preez and Louw, 2008). Chesbrough (2003) proposed the so-called "open innovation models" that are considered as the sixth generation of the innovation models. These SIs are mainly characterized by the continuous in/out flows of knowledge, between the organization and the external environment, which takes place throughout the innovation process. However, both kinds of SI models rely on a network of stakeholders, internal and external to the firm's organization, and on the progressive ideas selection (funnel mechanism) whereby most of the innovative ideas are discarded and only very few of them are considered worthy to be implemented.

\subsection{Leadership}

The INM model by Pirozzi and Ferulano (2016) derives by the CAF/EFQM/Baldridge models adopting the Total Quality Management (TQM) approach. Moreover, almost SMEs are organized according to the EN ISO 9001-2015 quality standard or adopt EFQM framework. Thus, it is wise that the EFQM's Leadership framework 
is used for the proposition of the advanced model INM*. The EFQM- Leadership is described through the following six areas (EFQM, 2013):

- To develop and share the organization's Mission and Vision;

- To develop a set of values and a code of ethics for the organization;

- To act as role models for the organization's values;

- Improvements throughout the organization are monitored, reviewed and championed by the Leaders;

- To identify the external stakeholders (Society, Partners, Customers) and to have regularly engage with them;

- To inspire people and create a culture of excellence;

- To assure that organization is agile and flexible enough to change effectively.

\section{Methodology and Its Development}

\subsection{Methodology}

The qualitative methodology adopted in this paper is deductive-inductive and it is able to combine the theoretical dimension with the empirical one (Blumberg et al., 2014). In this way, it is possible to detect the interaction between the theoretical frame of reference and the general empirical plan. We aim to obtain advantages generally recognized in both investigation plans (Dubois and Gadde, 2002).

For the construction of the advanced PMS model, it is aimed at grasping the interrelations arising between the theoretical-doctrinal framework and the similar models already existing. The objective is to devise an innovative PMS model for SMEs. Therefore, in a deductive way, we will deepen in the literature the issues related to the theme of PMS in the business environment. After we will come to the opportunity of a tool beyond traditional approaches. Inductively, through an analysis of the models already in use or proposed for other sectors, we identify a renewed prototype model (INM*) able to meet the specific needs of SMEs.

\subsection{The INM* Development}

The implementation of the advanced model INM* relies on the INM model by Pirozzi and Ferulano, 2016, The INM model is modified according to the insights obtained comparing the IC framework with the conceptual constructs of the entrepreneurship and the innovation capability. The SMA process is integrated in the INM*model creating aslo a connections between SMA and all INM* criteria. The development of the advanced model INM* is achieved through an established protocol based on the following four steps:

Step 1: The integration of SMA process into $\mathrm{INM}^{*}$ model is made assessing the intersection points in which the INM* criteria are involved by the six-stages SMA process. The ten INM* criteria consist of six enablers (1.Leadership; 2.Strategies and Policies, 3.Tangibles resources; 4.Relational capital; 5.Human capital; 6.Structural Capital) and four results (7.Results oriented to Human resources; 8.Results oriented to Citizen-users; 9. Results oriented to Social community; 10. Results oriented to Key performance). The crossing points between the $\mathrm{INM}^{*}$ criteria and SMA process are assessed so that specific sub-criteria in the INM* are included.

Step 2: A conceptual framework of the entrepreneurship process proposed by Morris et al. (1994), including the relevant input/outcome variables, is considered to shape a model of an entrepreneurial SME organization;

Step 3: The innovation capability, formed by the set of routines that are in charge to implement the knowledge components interaction and conversion processes (innovation engine), as well as all the determinants/results factors (Saunila, 2016), are integrated with the results of the step 1, in order to shape a framework that represents the basic organizational functioning of an innovative and entrepreneurial SME;

Step 4: The enablers, results, intermediate outputs and outcomes factors that connote the SME's model are classified and grouped according to the ten INM* criteria.

Following our research protocol, the description of each step is proposed below.

Step 1: Integration of SMA process into INM* model

Comparing the six-stages of SMA process with the ten INM* criteria the following relationships are assessed. First, some INM* criteria are considered involved during the entire SMA process, viz the "1. Leadership", "2. Strategies \& policies", "5. Human capital", "6. Structural capital" and, finally, the "10. Results oriented to Key performance". This is due to the pivotal role performed by the leadership and, furthermore, by the human and organizational capabilities needed to execute all the six stages of the SMA process. 
Moreover, the continuous involvement of the criterion "2. Strategies \& policies" is defined because this element can be modified any time by the leadership and the management. Indeed, these latter accomplish, respectively, the accountable and responsible tasks for the SMA process, enacting further modifications to the strategy, policies and to the management accounting, as soon as the enterprise's strategic repositioning is considered necessary. The management is an essential component of the human capital thus it will be included as sub-criterion of human capital criterion in the INM* structure.

The INM* criterion " 3 . Tangible Resources" is considered involved only in the steps 2 and 5 of SMA process, viz the "Exploitation of cost reduction opportunities". The INM* criterion 4. Relational Capital is involved only in steps 1 and 4 of SMA process namely "Collection of competitor information". For the SMA stage "1. Collection of competitor information" the involvement of the three criteria: "4. Relational Capital", "5. Human Capital" and "6. Structural Capital" was defined. This is because this stage relies on the communication of the organization with the external environment and upon the successive processing of the data, whereby a set of specific capabilities, detained at the individual and the organizational level, are needed. The relevant sub-criteria will be connoted, within the INM* structure, by means the synthetic statement "SMA step x", where $\mathrm{x}$ can range from 1 to 6 , indicating the specific activity making part of the SMA process. Since the implementation of the SMA process can be different, depending on the specific SME reality, more details about these sub-criteria will be produced during the PMS implementation stage.

Step 2: Entrepreneurial and innovative SME's model

The entrepreneurship model (Morris et al., 1994) exhibits the following inputs factors: environmental opportunities, entrepreneurial individual(s), organizational context, unique business concepts and resources. The entrepreneurial process, in turn, is considered articulated on four successive stages: identify opportunity, develop and refine concept, assess and acquire necessary resources, implementation. In order to capture the underlying variable nature of the entrepreneurship phenomenon, Morris et al. (1994) defined the entrepreneurial intensity (EI). This parameter is defined as a function of two variables: the frequency of entrepreneurship (FoE) and the degree of entrepreneurship (DoE) associated to the entrepreneurial event. The FoE is defined as the number of the entrepreneurial initiatives that the organization undertakes in a given period of time, while the DoE parameter, in turn, is defined as the measure of the innovativeness, risk taking and proactiveness, that connoted any entrepreneurial initiative. Therefore, it can be put as follows:

$$
E I=f(F o E, D o E)
$$

This paper considers the Input-Outcome model (Morris et al., 1994) to assess the characteristics of the entrepreneurship to be captured by the INM* framework. The relevant parameters comprised in our advanced model are assigned to the INM*'s Enablers/Results as indicated below.

- Unique business concepts; $\rightarrow$ INM* enabler 2.Strategies and policies;

- $\quad$ Resources $\rightarrow \mathrm{INM}^{*}$ enabler 3.Tangible resources;

- Environmental opportunies $\rightarrow$ INM enabler 4.Relational capital;

- Entrepreneurial individual(s), Management,

Degree of entrepreneurship (DoE) at individual level; $\rightarrow$ INM enabler 5.Human capital;

- Organizational context, Identify opportunity,

Develop and refine concepts, Access \& acquire resources,

Implementation, Degree of entrepreneurship (DoE) at

organizational level, Frequency of entrepreneurship (FoE),

Entrepreneurial Intensity (EI); $\rightarrow$ INM enabler 6.Structural capital;

- $\quad$ Employment, personal benefits; $\rightarrow$ INM enabler 7.Results to HR;

- $\quad$ New products, services, processes; $\rightarrow$ INM enabler 8.Results to Citizen-users;

- A going venture; $\rightarrow$ INM enabler 9.Results to Social Community;

- Profit, asset \& revenue growth, failure or loss,

value creation; $\rightarrow$ INM enabler 8.Results to Key Performance;

Step 3: Integration of the innovation capability in the SME model

Innovation capability in SMEs plays a relevant role. Minna Saunila (2016) found that the innovation capability 
in SME organizations is affected by several factors that can be represented by seven determinants and two enablers. The descriptions of such factors are as literally reported in Table 1 (Saunila, 2016; Saunila and Ukko, 2013; Saunila et al., 2014).

Table 1. Determinants and Enablers' description

\section{DETERMINANTS}

Leadership culture: The overall atmosphere of the organization that supports and motivates innovation, and also leadership that facilitates innovation.

Work climate and well-being: Represents the well-being of the employees and further the work climate for innovation development, including collaboration and values.

Ideation and organizing structures: Related to the structures and systems that successful innovation requires. This includes the generation, development and implementation of innovations, and the ways how the work tasks of the organization are organised.

Know-how development: Skills and knowledge of the employees play an important role in innovation capability. This includes the utilisation of knowledge as well as the improvement of employee skills.

Exploiting external knowledge: The importance of the proper behaviour of exploiting external networks and knowledge to the overall organizational innovation capability.

Regeneration: An organization's ability to learn from earlier experiences and to use those experiences to create innovations and develop their operations.

Individual activity: Employees' individual innovation capability and activity are needed to form the organization's overall innovation capability.

\section{ENABLERS}

Resources: Organizational and human resources that make it possible to develop organizational capability to produce innovations.

Vision \& strategy: Vision and strategy that direct an organization's innovation activities and capability development.

Analysing the determinants and enablers related to the innovation capability (Saunila, 2016) and the INM* criteria, we propose a congruence matrix (Figure 3) composed of six aspects (a, b, c, d, e, f) that are worthy to be highlighted in more details.

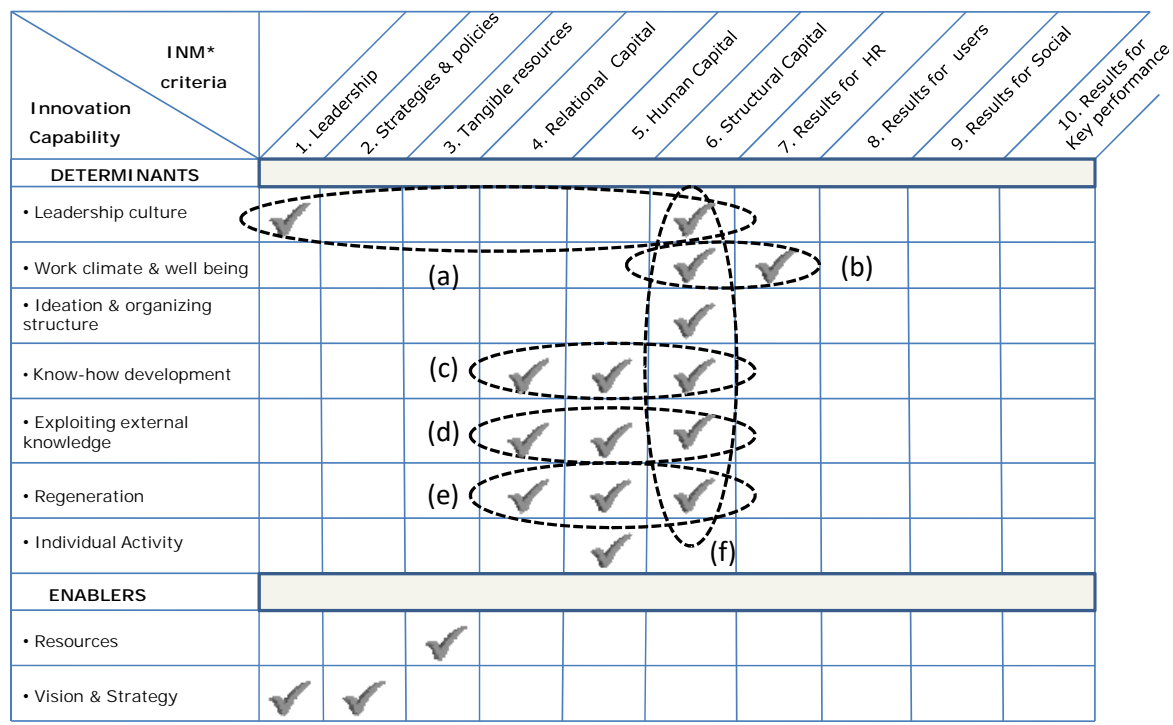

Figure 3. Congruence matrix of Innovation capability factors vs INM* criteria Source: Our elaboration from Saunila (2014) and Pirozzi and Ferulano (2016) studies. 


\section{(a) Organizational culture as a Structural Capital component}

The determinant "Leadership Culture" (Saunila, 2016) is divided in two different parameters, viz the Leadership and the Organizational Culture. Indeed, Edgar Schein $(1984,1990)$ argued that the leadership and organizational culture processes are inseparable, the organizational culture is a leadership outcome and, furthermore, that the main task of the leadership consists in manipulating the culture. Moreover, the organizational culture is a collective phenomenon that resides within the organization being retained by the organizational routines. Indeed, the Structural Capital is the place where the organizational culture resides (Sánchez-Cañizares et al., 2007).

\section{(b) The work climate and the well being of employees}

This determinant is divided in two different topics: organizational climate and well being of employees. According to D'Amato and Majer (2005), the organizational climate (OC) conceptual construct is defined as the set of policies, practices and procedures recognized and shared within organizations. This is that cognitive appraisal of the company's priorities which has the power to drive the individual, the group and the organization's behaviour, as a whole. There is a wide consensus about the crucial role played by the OC in the organization's development and effectiveness (Kozlowski and Klein, 2000; D'Amato and Majer, 2005; Quaglino and Mander, 1987; Quaglino, 2010). Indeed, according to D'Amato and Majer (2005), it is widely accepted the causal relationship between $\mathrm{OC}$ and the different outcomes, both at individual and organizational levels, as indicated below:

- job satisfaction and stress (D'Amato and Majer, 2005);

- implementation of new technologies (Klein et al., 2001);

- $\quad$ innovation (West and Anderson, 1996);

- customer satisfaction or service quality perceptions (Schneider et al., 1998; Schneider et. al., 2002; D'Amato and Majer, 2005);

- $\quad$ performance (West et. al., 1998; Colquitt, 2001; Colquitt et al., 2002);

- team work-satisfaction and commitment (Gonzalez-Roma et al., 2002).

Considering the OC definition proposed by D'Amato and Majer (2005), it can be assumed as a sub-criterion of the INM*'s criterion "6.Structural capital" acting as an enabler for the innovation capability and the superior performance achievement. Moreover, the "well being of employees" is to be included as sub-criteria of criterion "7.Results for human resources".

\section{(c, $d, e)$ - Knowledge components and knowledge dynamics}

The IC components are all involved in internal know-how development, external knowledge exploitation and regeneration parameters defined by Saunila (2014), cooperating to creation and evolution of firm's innovation capability. Nevertheless the process of acquisition, trasformation and internal-external exchange of knowledge, that is subtended to the innovation process, is more detailed by the conceptual framework depicted in Figure 2 so that this intermediate result are used in INM* instead of three parameters defined in Saunila's model.

Since the embrained and embodied components are owned by individuals, these elements was included into the "5.Human capital" criterion. Viceversa, the encoded and embedded components are considered components of the "6.Structural capital" criterion because they reside at collective level (Lam, 2000). Finally, the exchange of knowledge through externalization/internalization processes acting both within the organization and between this latter and the external environment is assumed to be included into "4.Relational capital" criterion.

This work shows that these specific aspects contribute to better highlight the important role of the complementarity property of the IC components (Ling, 2012) and the related dynamic dimension of the IC (Stam, 2010; Kianto, 2007; Ferraro and Cristiano, 2019).

\section{(f) The pivotal role played by the Structural Capital}

The structural capital can be considered the hinge element that within the SME organization elaborates the inputs and produces the outcomes. Indeed, the structural capital realizes the entrepreneurial process and its coordination, also providing the innovation capability support. The innovation capability function, that is referred in this work as "innovation engine", includes the behavioural and cognitive regularities (Becker, 2004) underlying the three basic innovation sub-processes defined by Pavitt (2003). Lastly, this work proposes, in the Figure 4, the model related to the entrepreneurial and innovative SME functioning.

Comparing the model proposed by Morris et al. (1994) with the model depicted in the Figure 4, six different new concepts are introduced by this work: (i) the waterfall nature of the entrepreneurial process; (ii) the trigger 
mechanism (external clue) between one stage and the successive of the waterfall process; (iii) the integration of the innovation engine within the entrepreneurship process; (iv) the trigger mechanism that is activated when a macro-phase cannot be accomplished whereby a problem-solving stage is necessary and, as a consequence, the innovation engine is started; (v) the definition of the intermediate outputs represented by the organizational culture, organizational climate and the ambidexterity properties of firm's organization; (vi) the Entrepreneurship Intensity (EI) was defined by Morris et al. (1994) as output, but this work suggests that it is an intermediate result of the entrepreneurship process, so that this work assumes EI as a structural characteristic connoting the "raison d'être" of the firm.

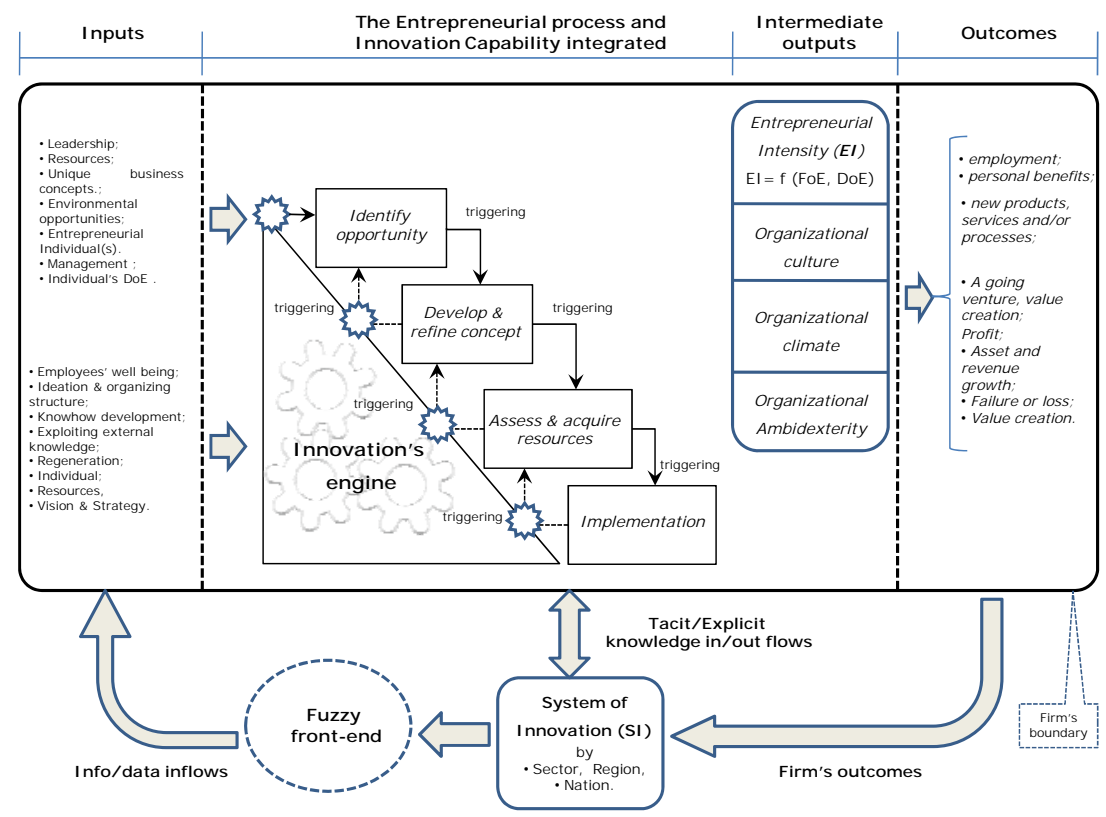

Figure 4. An integrated view of entrepreneurial process and Innovation capability

Source: Our elaboration from Morris et al. (1994), Saunila (2016), Trott (2005), du Preez andLouw (2008), Chesbrough (2003).

The external environment surrounding the firm organization is also included adopting the "open" and "closed" SI paradigms. Indeed, more than one SI model can co-exist within that same organization in a given period of time (Rothwell, 1994). Thus, a firm can utilize a SI model for some entrepreneurial initiatives and, vice versa, to comply with another SI model for the others.

According to Rahman and Ramos (2011), there is "a growing trend of the adoption of using external knowledge acquisition strategies among firms with employee class size of 50-249, i.e., the SMEs". These authors found out that the average rate of SMEs, across all the industrial sectors, that adopt an open innovation system strategy is $71 \%$. This value ranges from $82 \%$ of the high-tech SMEs to $65 \%$ of the low-tech SMEs. Finally, they stated that "The trend of adoption is significant and with proper knowledge transfer, participation rate of SMEs can be improved further".

Step 4: Comparing SME's model with INM* criteria

We propose the description of the INM* criteria following the previous step 2 and the INM model. The main criteria are (Table II): 1) leadership; 2) strategies and policies; 3) tangible resources; 4) relational capital; 5) human capital; 6) strucutural capital; 7) results oriented to human resources; 8) results oriented to Citizen-users; 9) results oriented to Social community; 10) results oriented to key performance. 
Table 2. The INM* criteria

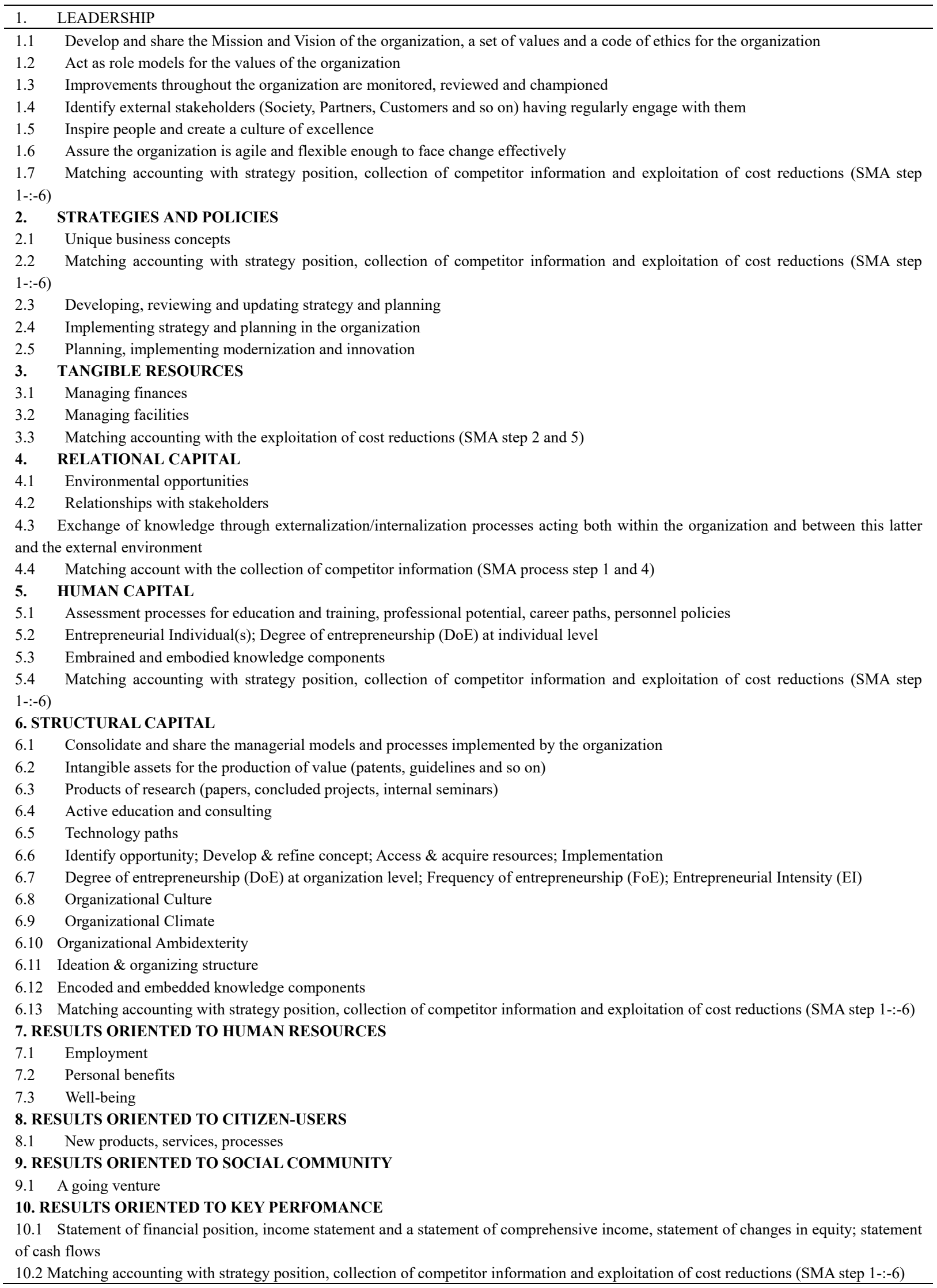


The INM* is fully described by 6 enablers criteria, further detailed in 36 sub-criteria, and 4 results criteria detailed in 7 sub-criteria. The overall INM* structure is depicted in the Figure 5 reported below. The results criteria and the sub-criteria related to the accomplishment of the six stages of the SMA process, remained intentionally defined with a low level of detail. Indeed, they will be further described in more details depending on the operational reality connoting the firm involved in the application phase (Phase B). Moreover, the enabler "organizational context", proposed by Morris et al. (1994), is removed because it is considered sufficiently detailed through the introduction of the "Organizational Culture", the "Climate" and the "Ambidexterity" enablers.

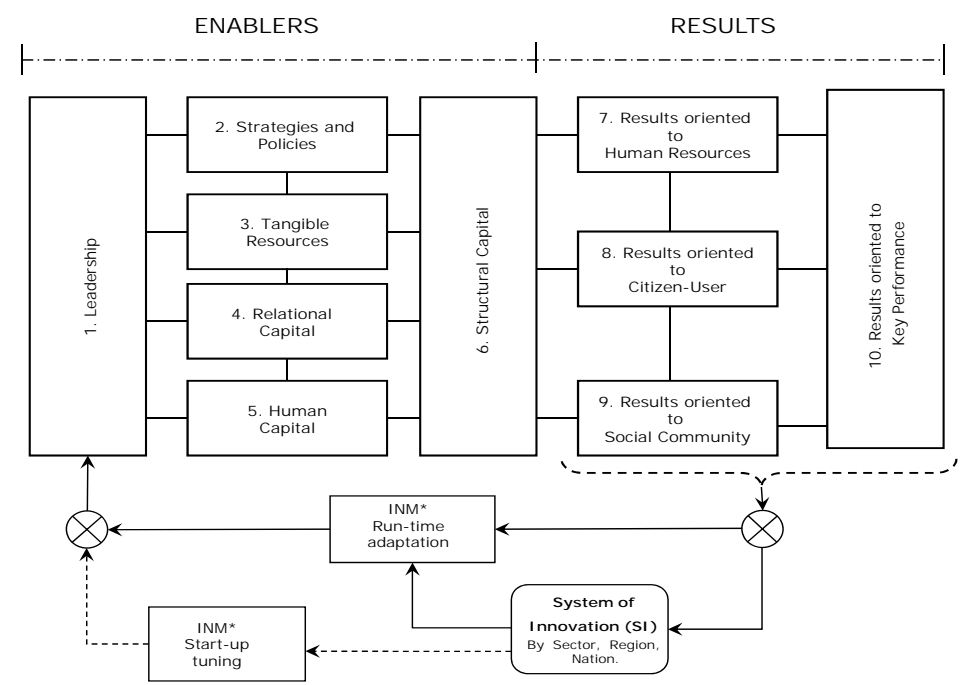

Figure 5. INM* Model for SMEs - Conceptual Framework

Source: Our elaboration from Pirozzi and Ferulano (2016).

\subsection{INM* Feedback Chains}

A feedback loop was included in the INM* framework intended to perform an initial set-up to be carried at the start-up stage. This initial tuning will be shaped according to the different systemic characteristics exhibited by the SI, at sector/region/nation level, in which the specific firm carries out its activities and, moreover, depending on the different life cycle stage connoting the enterprise in a given time period (Quinn and Cameron, 1983). However, another tuning mechanism, but acting during the fully operational stage, was already included into the INM (Pirozzi and Ferulano, 2016) so that it was inherited by INM*.

This set-up dynamically occurs during the entire life cycle of the INM*, according to the evolution of the business priorities, changing values of some constants or coefficients (e.g. benchmark, constants, transfer functions) relevant to specific performance parameters. In this way it would be possible to adapt the INM* both to the continuous dynamic shaping of strategy and to changes arising from the external environment over the time (Eccles, 1991). The external environment is represented by the feedback signal generated by the SI that continuously contributes in this manner to the INM* run-time adaptation.

\section{Results and Discussion}

\subsection{IC Implementation in SMEs and RBV approach to SMA}

Some implications are adopted as main drivers of this paper. The first one points out that within the SMA literature the more internal and resources based view of the firm was mostly neglected so far. The second is represented by the difficulty to bring the IC to the application phase despite the overwhelming evidence of the importance of the IC framework and, finally, the IC researchers devoted scant attention to the SMEs organizations so far. However, this paper proposes a viable solution to answer these issues through the adoption of three concepts.

The first consisted in the integration of the SMA process into performance measurement systems INM*. In this way, the correct execution of the activities needed to implement the SMA process are clearly defined, the relations with IC are also detected, as well as the properly and timely tracking actions are assured. The second concept is represented by the usage of the IC framework as a "lens" (Marr, 2005) that this work adopted gathering new insights in the research fields of the entrepreneurship, innovation, organization theory, management, psychology 
and, finally, strategic management accounting. The third concept is the represented by the pursuing of "managerial significance" (Becker and Huselid, 2006; Bazerman, 2005) of the IC research (Pirozzi and Ferulano, 2016). Indeed, the causal relationships between IC and performance, detected and assessed in the course of present work, were hard-wired into INM* allowing managers and practitioners to verify and validate the actual impact of each IC components on the firm's performance.

\subsection{What Really Is the Dynamic Dimension of the IC}

About the "vexata quaestio" of what really consists the dynamic dimension of the IC (Kianto, 2007; Stam, 2010) this work suggests that significant insights on this specific topic can be gathered considering the basic elements that make up each IC components. More precisely, as far as concerns the structural capital, the properties and characteristics of organizational routines should be primarily considered. Moreover, for the human capital and the relational capital, the several components of the knowledge, as well as the relevant conversion processes underlying them, should be evaluated. Indeed, this work adopts such approach to explore the dynamic behaviour, both internal and external, of the IC components, attaining some interesting results relating to the dynamic dimension of the IC and the complementarity that exists between its components.

\section{Conclusions}

\subsection{Practical Contribution}

The INM* model deals with the challenge to implement all the measurement functions (IC and financial and non-financial data) in an integrated measurement system as advanced system by PMS (Davis and Albright, 2004; Nielsen, 2019; van der Merwe and Visser, 2008), to assure the interpretation and coherence assessment of SMEs activities.

\subsubsection{A Software Platform Development to Support INM* Framework Usage}

Starting from the SME organization model and the proposed INM* model, an in-depth functional analysis could be carried out in order to detail the user requirements, as well as the software specifications, necessary to feed the development of a software platform eventually based on Artificial Intelligence (A.I.) technologies. This software system could be leased to the SMEs, through internet, under a services providing contract. In this way the SMEs could have the chance to use A.I. technologies usually adopted only by larger organizations that can easily afford the financial efforts required by such initiatives. Moreover, the SMEs could use a benchmark parameters database tailored according to the environment (sector, region, nation) in which the specific SME operates so that either the initial set-up or the run-time adaptation of the INM*, would be as much as possible easy and fast. On the other side, the Software Houses and A.I. technologies providers could have a strong motivation to invest in the construction of such application because they could create an new accessible market represented by the huge SMEs population so that the return on investments will be drastically improved;

\subsubsection{Advantages for Practitioners Deriving from the INM* Usage}

These advantages are mainly related to commercial/marketing aspects and the effectiveness of consulting interventions at the SMEs premises. Indeed, the origin of the INM framework (Pirozzi and Ferulano, 2016) derives from the widely diffused CAF-EFQM-Baldrige models so that this makes the INM* portable, with a reasonable effort, on a wide accessible market represented by the firms that already use such conceptual framework. Moreover, the $\mathrm{INM}^{*}$ could represent a specific approach of the future consulting interventions devoted to the application of a management control system inside a SME organization.

Indeed, such initiative could be tailored using, in the first instance, the SME model proposed by this work in order to capture, as much as possible, the specificities of the SME where the initiative takes place. Thus, according to the results of this first step, the successive step, consisting in the customization of the INM*, will be highly facilitated so that it could be quickly accomplished. Finally, the reduction of performance measurement to an unique system will reduce drastically the financial effort to implement and manage it and, also, the organizational stress represented by the application of such system within the organization.

\subsection{Research Contribution}

This paper produces three interesting intermediate results, namely the innovative and entrepreneurial SME model (Figure 4), the interactions and knowledge conversion schema between the IC components that take place throughout the innovation process (Figure 2) and, finally, the relationships between the SMA process and the $I_{N M}^{*}$ criteria (Figure 3). The final goal subtended to this work was achieved throughout an integration process that involved different conceptual frameworks representing the entrepreneurship process, the innovation capability and the SMA process. The integration process adopted, in turn, produced some interesting insights 
related to (i) the intimate conformation of the structural capital; (ii) the IC complementarity and its dynamic dimension; (iii) the creation and the in/out flows of knowledge that support the generation and the continuous updating of the innovation capability; (iv) the direct involvement of the IC components in the execution and control of the SMA process.

This research also suggests that the organizational culture, the organizational climate and the ambidexterity are intermediate outputs allocated within the structural capital. The latter, in turn, results heavily connoted by these sub-processes, meanwhile it provides the building blocks, namely the organizational routines, in order to shape these important organizational functions. Finally, in the course of the work, emerged clearly the role of the structural capital as the agent that implements, by means the trigger mechanisms, the overall coordination of the entrepreneurship process and the ignition of the innovation's engine every time a problem-solving stage is needed.

\subsection{Limitations and Future Research}

\subsubsection{INM* - Conceptualization Phase}

This paper accomplishes just the conceptualization phase of the PMS development and further steps are still to be covered. Therefore, additional efforts are necessary in order to have the INM* ready for the application phase. Indeed, the PMS development life cycle is usually structured in 4 stages: (a) Conceptualization, (b) Selection and development of measures, (c) Data collection and Processing, (d) Reporting and results utilization (Adair et al., 2006). Moreover, this life-cycle is not to be intended as a linear process but rather as a dynamic one, with feedback actions acting between the several stages. Therefore, the PMS conceptual framework produced in the (a) Conceptualization stage, could be modified depending on the feedbacks deriving from the execution of the next stages (Pirozzi and Ferulano, 2016).

\subsubsection{Further Analysis for SMA/INM* Intersection Point}

The sub-criteria related to the intersection points between the SMA process and the INM* criteria should be further detailed within an empirical research implemented throughout specific interviews with managers acting in the SME sector. Moreover, in the development of the INM* conceptual framework, specific multidimensional conceptual constructs to be measured, are clearly indicated. Therefore, within the next phase (Phase B), a literature review should be carried out in order to select the specific measurements tools for the organizational culture, climate and ambidexterity.

\subsubsection{INM* Complexity}

The INM* is connoted by many variables, viz 43 sub-criteria in total, some of them showing a multidimensional nature. Moreover, several factors are linked by causal relations that evolve over the time. In order to make the usage of the INM* quick and easy, the development of a software application to support the utilization of the INM*, could be envisaged. If this IT support would be really implemented, the limitation here referred could represent, vice versa, a strength point. Indeed, Bernard Marr (2006) stated that an IT support could represents a "vital enablers and enhancers" for the organizations that face the challenge to adopt a strategic PMS. Therefore, for those organizations "that want to unleash the full potential of Strategic Performance Management, there is no alternative to installing purpose built software applications" (Marr, 2006).

\subsection{The Future Research}

\subsubsection{IC research-The Third and Fourth Stages}

Recently, it was proposed a "fourth stage of IC research based on IC eco-systems of cities and nations" intended to "complement (not oppose) the third stage of IC research" (Dumay, 2013; Dumay and Garanina, 2013; Dumay et al., 2017; Guthrie et al., 2017; Secundo et al., 2018). Additionally, Leif Edvinsson (2013) maintains that this approach should be able to "establish a deeper understanding of a higher form of capital" through the consideration of the relational capital owned by the networks and, also, applying a "cross-disciplinary systematised perspectives that will increase the IC consciousness". This research suggests that to lead the analysis of such phenomenon, the third stage approach, the usage of the IC framework as a "lens" (Marr, 2005) and the adoption of the SI and the SMA paradigms could be appropriate to the scope.

Furthermore, this work maintains that the so organized research approach could be considered as the natural evolution of the third stage. Indeed, among the results shown by this work, the consideration of the dynamic in/out migration of the knowledge between an organization and a SI (Mazzucato, 2014, Chesbrough, 2003), the interactions within the IC components stored inside the firm (Nonaka, 1994; Lam, 2000) and, finally, the crossing points between the SMA process and INM* criteria, seem pertinent to the IC eco-systems issue. Therefore, the 
following research question could be defined: RQ1: Does the IC research really need a fourth stage in order to answer to the "eco-systems" issue or, vice versa, an appropriate evolution of the third stage could be more effective to reach this purpose?

\subsubsection{Strategic Management Accounting (SMA) and the IC}

This paper shows that all the IC components participate to the implementation of the SMA process. The latter, in turn, can be embedded in the INM* integrated framework so as to assure its proper implementation and the timely control. Moreover, it was pointed out that the structural capital represent the hinge element between input and output of the entrepreneurial process. In this perspective, it define a could be specific the research question: RQ2: Can the IC framework successfully represent the dynamic relation and the alignment actions that should take place in the SME organizations between the Leadership, Strategy, Management, and the Management Accounting?

\section{References}

Abdulsaleh, A. M., \& Worthington, A. C. (2013). Small And Medium-Sized Enterprises Financing: A Review of Literature. International Journal of Business and Management, 8(14), 36-54. https://doi.org/10.5539/ijbm.v8n14p36

Adair, C. E., Simpson, E., Casebeer, A. L., Birdsell, J. M., Hayden, K. A., \& Lewis, S. (2006). Performance measurement in healthcare: part II - state of the science findings by stage of the performance measurement process. Healthcare Policy, 2(1), 56-78. https://doi.org/10.12927/hcpol.2006.18338

Anderson, N., De Dreu, C., \& Nijstad, B. A. (2004). The Routinization of Innovation Research: A Constructively Critical View of the State-of-the-Science. Journal of Organizational Behavior, 25(2), 147-173. https://doi.org/10.1002/job.236

Baccarini, M., Castellini, M., Quercini, A. M., \& Vagnoni, E. (2008). La rappresentazione del Capitale Intellettuale nelle organizzazioni Sanitarie. Dossier No. 164-2008, Agenzia Sanitaria e Sociale Regione Emilia Romagna, Bologna (Italy).

Barney, J. B. (1991). Firm resources and sustained competitive advantage. Journal of Management, 17(1), 9-120. https://doi.org/10.1177/014920639101700108

Bazerman, M. H. (2005). Conducting influential research: the need for prescriptive implications. Academy of Management Review, 30(1), 25-31. https://doi.org/10.5465/amr.2005.15281417

Becker, B. E., \& Huselid, M. A. (2006). Strategic human resources management: where do we go from here? Journal of Management, 32(6), 898-925. https://doi.org/10.1177/0149206306293668

Becker, M. C. (2004). Organizational routines: a review of the literature. Industrial and Corporate Change, 13(4), 643-677. https://doi.org/10.1093/icc/dth026

Becker, M. C., Lazaric, N., Nelson, R. R., \& Winter, S. G. (2005). Applying organizational routines in understanding organizational change. Industrial and Corporate Change, 14(5), 775-791. https://doi.org/10.1093/icc/dth071

Blackler, F. (1995). Knowledge, knowledge work and organizations: an overview and interpretation. Organizational Studies, 16(6), 1021-1046. https://doi.org/10.1177/017084069501600605.

Bontis, N. (1999). Managing organizational knowledge by diagnosing intellectual capital: framing and advancing the state of the field. Journal of Technology Management, 18(5/6/7/8), 433-466. https://doi.org/10.1504/IJTM.1999.002780

Busenitz, L. W., West, G. P., Shepherd, D., Nelson, T., Chandler, G. N., \& Zacharakis, A. (2003). Entrepreneurship Research in Emergence: Past Trends and Future Directions. Journal of Management, 29(3), 285-308. https://doi.org/10.1016/S0149-2063(03)00013-8

Cadez, S., \& Guilding, C. (2008). An exploratory investigation of an integrated contingency model of strategic management accounting. Accounting, Organizations and Society, 33(7-8). 836-863. https://doi.org/10.1016/j.aos.2008.01.003

Carrel, J. (2007). Intellectual capital: An inquiry into its acceptance. Business Renaissance Quarterly, 2(1).

Carrell, J. (2010). An epistemology of intellectual capital and its transition to a practical application. In O'Sullivan, K. J. (Ed.), Strategic Intellectual Capital Management in Multinational Organizations: Sustainability and Successful Implications. Business Science Reference-IGI Global, Hershey PA. 
https://doi.org/10.4018/978-1-60566-679-2.ch002

Castela, B. M. S., Ferreira, F. A. F., Ferreira, J. J. M., \& Marques, C. S. E. (2018). Assessing the innovation capability of small- and medium-sized enterprises using a non-parametric and integrative approach. Management Decision, 56(6), 1365-1383. https://doi.org/10.1108/MD-02-2017-0156

Chesbrough, H. (2003). Open Innovation: The New Imperative for Creating and Profiting from Technology. Harvard Business School Press.

Cinquini, L., \& Tenucci, A. (2007). Is the adoption of strategic management accounting techniques really 'strategy driven'? Evidence from a survey. Munich Personal RePEc Archive, MPRA Paper No. 11819, Conference Paper, Cost and Performance in Services and Operations, Trento, Italy.

Collins, H. M. (1993). The structure of knowledge. Social Research, 60(1), 95-116.

Colquitt, J. A. (2001). On the dimensionality of organizational justice: A construct validation of a measure. Journal of Applied Psychology, 86(3), 386-400. https://doi.org/10.1037/0021-9010.86.3.386

Colquitt, J. A., Noe, R. A., \& Jackson, C. L. (2002). Justice in teams: Antecedents and consequences of procedural justice climate. Personnel Psychology, https://doi.org/10.1111/j.1744-6570.2002.tb00104.x

D’Amato, A., \& Majer, V. (2005). Il vantaggio del clima - la ricerca del clima per lo sviluppo organizzativo (1st ed.). Raffaello Cortina Editore, Milano.

Davis, S., \& Albright, T. (2004). An investigation of the effect of balanced scorecard implementation on financial performance. Management Accounting Research, 15(2), 135-153. https://doi.org/10.1016/j.mar.2003.11.001

Docherty, M. (2006). Primer on open innovation: Principles and practice. PDMA Visions, 30(2), 13-17.

Du Preez, N. D., \& Louw, L. (2008). A Framework for Managing the Innovation process. Management of Engineering \& Technology PICMET $2008 \quad$ - International Conference, Portland. https://doi.org/10.1109/PICMET.2008.4599663

Dubois, A., \& Gadde, L. E. (2002). Systematic Combining - An abductive approach to case research. Journal of Business Research, 55, 553-560. https://doi.org/ 10.1016/S0148-2963(00)00195-8

Dumay, J. (2013). The third stage of IC: towards a new IC future and beyond. Journal of Intellectual Capital, 14(1), 5-9. https://doi.org/10.1108/14691931311288986

Dumay, J. (2016). A critical reflection on the future of intellectual capital: from reporting to disclosure. Journal of Intellectual Capital, 17(1), 168-184. https://doi.org/10.1108/JIC-08-2015-0072

Dumay, J., \& Garanina, T. (2013). Intellectual capital research: a critical examination of the third stage. Journal of Intellectual Capital, 14(1), 10-25. https://doi.org/10.1108/14691931311288995

Dumay, J., Guthrie, J., Ricceri, F., \& Nielsen, C. (2017). The past, present and future for intellectual capital research: An overview. In J. Guthrie, J. Dumay, F. Ricceri and C. Nielsen (Eds.), The Routledge Companion to Intellectual Capital: Frontiers of Research, Practice and Knowledge (pp. 1-18). https://doi.org/ 10.4324/9781315393100.ch1

Eccles, R. G. (1991). The performance measurement manifesto. Harvard Business Review, 69(1), 131-137.

Edquist, C. (2001). The systems of innovation approach and innovation policy: an account of the state of the art. DRUID Conference, Aalborg. Retrieved from https://www.researchgate.net/publication/228823918_The_Systems_of_Innovation_Approach_and_Innovat ion_Policy_An_Account of the State_of the Art (accessed 19 may 2017).

Edvinsson, L. (2013). IC 21: reflections from 21 years of IC practice and theory. Journal of Intellectual Capital, 14(1), 163-172. https://doi.org/10.1108/14691931311289075

EFQM. (2013). The EFQM Model in Action- Leadership - Basic Assessment. Retrieved from http://www.efqm.org/sites/default/files/leadershipassess.pdf

European CAF Resources Centre. (2006). CAF 2006 - the common assessment framework (CAF). EIPA, Brussels, Retrieved from http:/www.eipa.eu/files/File/CAF/Brochure2006/English_2006.pdf

European Commission. (2015). User guide to the SME Definition. Publications Office, Luxembourg.

European Commission. (2017). Annual Report on European SMEs 2016/2017. Final Report, Editor Karen Hope.

Ferraro, O., \& Cristiano, E. (2019). Valuation of Human Capital: A Review of Studies on Quali-Quantitative 
Methods. International Journal of Business and Management, 14(11), 165-178. https://doi.org/10.5539/ijbm.v12n2p83

Firer, S., \& Stainbank, L. (2003). Testing the relationship between intellectual capital and a company's performance: Evidence from South Africa. Meditari Accountancy Research, 11(1), 25-44. https://doi.org/10.1108/10222529200300003.

Freeman, C. (1995). The "National System of Innovation" in Historical Perspective. Cambridge Journal of Economics, 19(1), 5-24.

Gartner, W. B. (1990). What Are We Talking About When We Talk About Entrepreneurship. Journal of Business Venturing, 5(1), 15-28. https://doi.org/10.1016/0883-9026(90)90023-M

Gonzalez-Roma, V., Peirò, J. M., \& Tordera, N. (2002). An Examination of the antecedents and moderator influences of climate strength. Journal of Applied Psychology, 87(3), 465-473. https://doi.org/10.1037/0021-9010.87.3.465

Grant, R. M. (1991). The resources-based theory of competitive advantage: implications for strategy formulation. California Management Review, 33(3), 114-135. https://doi.org/10.2307/41166664

Guilding, C., Cravens, K. S., \& Tayles, M. (2000). An international comparison of strategic management accounting practices. Management Accounting Research, 11(1), 113-135. https://doi.org/10.1006/mare.1999.0120

Guthrie, J., Dumay, J., Ricceri, F., \& Nielsen, C. (2017). The Routledge Companion to Intellectual Capital: Frontiers of Research, Practice and Knowledge. Routledge. London. https://doi.org/10.4324/9781315393100

Guthrie, J., Ricceri, F., \& Dumay, J. (2012). Reflections and projections: a decade of intellectual capital accounting research. British Accounting Review, 44(2), 68-82. https://doi.org/10.1016/j.bar.2012.03.004

Hall, R. (1993). A framework linking intangibles resources and capabilities to sustainable competitive advantage. Strategic Management Journal, 14(8), 607. https://doi.org/10.1002/smj.4250140804

Hannan, M. T., \& Freeman, J. (1977). The Population Ecology of Organizations. American Journal of Sociology, 82(5), 929-964. https://doi.org/10.1086/226424

Hannan, M. T., \& Freeman, J. (1984). Structural Inertia and Organizational Change. American Sociological Review, 49, 149-164. https://doi.org/10.2307/2095567.

Herrmann, P. (2005). Evolution of strategic management: the need for new dominant designs. International Journal of Management Reviews, 7(2), 111-130. https://doi.org/10.1111/j.1468-2370.2005.00108.x

Hodgson, G. M. (1993). Economics and Evolution. Cambridge: Polity Press. https://doi.org/10.3998/mpub.14010.

Hogan, S. J., Soutar, G. N., McColl-Kennedy, J. R., \& Sweeney, J. C. (2011). Reconceptualizing professional service firm innovation capability: scale development. Industrial Marketing Management, 40(8), 1264-1273. https://doi.org/10.1016/j.indmarman.2011.10.002

Hudson, M., Smart, A., \& Bourne, M. (2000). Theory and practice in SME performance measurement systems. International Journal of Operations \& Production Management, 21(8), 1096-1115. https://doi.org/10.1108/EUM0000000005587

International Accounting Standards Board (IASB). (2015). International Financial Reporting Standard $($ IFRS $®$ ) for Small and Medium-sized Entities (SMEs). IFRS Foundation, London, UK.

Ittner, C. D., Larcker, D. F., \& Meyer, M. W. (2003). Subjectivity and the weighting of performance measures: evidence form a balanced scorecard. Accounting Review, 78(3), 725-758. https://doi.org/10.2139/ssrn.395241

Jaruzelski, B., Dehoff, K., \& Bordia, R. (2006). The Booz Allen Hamilton Global Innovation 1000. Retrieved from http://http://www.urenio.org/wp-content/uploads/2009/01/global-innovation-1000-2006.pdf

Jennings, P. L., \& Beaver, G. (1997). The Performance and Competitive Advantage of Small Firms. A Managerial Perspective. International Small Business Journal, 15(2). https://doi.org/10.1177/0266242697152004

Kianto, A. (2007). What do we really mean by dynamic intellectual capital? International Journal of Learning and Intellectual Capital, 4(4), 342-356. https://doi.org/10.1504/IJLIC.2007.016332 
Klaila, D., \& Hall, L. (2000). Using intellectual assets as a success strategy. Journal of Intellectual Capital, 1(1), 47-53. https://doi.org/10.1108/14691930010324133.

Klein, K. J., Conn, A. B., \& Sorra, J. S. (2001). Implementing computerized technology: An organizational analysis. Journal of Applied Psychology, 86(5), 811-824. https://doi.org/10.1037/0021-9010.86.5.811

Kogut, B., \& Zander, U. (1992). Knowledge of the firm, combinative capabilities, and the replication of technology. Organization Science, 3(3), 383-397. https://doi.org/10.1287/orsc.3.3.383

Kozlowski, S. W. J., \& Klein, K. (2000). A multilevel approach to theory and research in organizations: contextual, temporal, and emergent processes. In Klein, K. J. Kozlowski, S.W.J. (Eds.), Multilevel Theory, Research and Methods in Organizations. Jossey-Bass, San Francisco. https://doi.org/10.2307/3094811

Lam, A. (2000). Tacit Knowledge, Organizational Learning and Societal Institutions: An Integrated Framework. Organizational Studies, 21(3), 487-513. https://doi.org/10.1177/0170840600213001

Langfield-Smith, K. (2008). Strategic management accounting: how far have we come in 25 years? Accounting, Auditing \& Accountability Journal, 21(2), 204-228. https://doi.org/10.1108/09513570810854400

Langlois, R. N. (1992). Transaction-cost economics in real time. Industrial and Corporate Change, 1, 99-127. https://doi.org/10.1093/icc/1.1.99

Lansisalmi, H., Kivimaki, M., Aalto, P., \& Ruoranen R. (2006). Innovation in Healthcare: A Systematic Review of Recent Research. Nursing Science Quarterly, 19, 66-72. https://doi.org/10.1177/0894318405284129

Lawrence, P. R., \& Lorsch, J. W. (1967). Differentiation and Integration in Complex Organizations. Administrative Science Quarterly, 12, 1-47. https://doi.org/10.2307/2391211

Lazonick, W. (2013). The Theory of Innovative Enterprise: Methodology, Ideology, and Institutions. In Jamee K. Moudud, Cyrus Bina, and Patrick L. Mason (Eds.), Alternative Theories of Competition: Challenges to the Orthodoxy. Routledge. https://doi.org/10.4324/9780203102671

Lazonick, W., \& O'Sullivan, M. (1998). Corporate Governance and the Innovative Economy: Policy Implications. STEP Report R-03, STEP Group, Oslo, Norway.

Lev, B. (2003). Intangibles, Etas, Milan.

Lev, B., \& Daum, J. H. (2003). Intangible assets and the need for a holistic and more future-oriented approach to enterprise management and corporate reporting. Retrieved from http://www.juergendaum.de/articles/paper\%2010-pma_ic_symp_lev_daum.pdf

Liao Y., \& Barnes J. (2015). Knowledge acquisition and product innovation flexibility in SMEs. Business Process Management Journal, 21(2), 1257-1278. https://doi.org/10.1108/BPMJ-05-2014-0039

Ling, Y. H. (2012). A Study on the Influence of Intellectual Capital and Intellectual Capital Complementarity on Global Initiatives. The Electronic Journal of Knowledge Management, 10(2), 154-162.

Lord, B. L. (1996). Strategic Management Accounting: The Emperor's new clothes? Management Accounting Research, 7, 347-366. https://doi.org/10.1006/mare.1996.0020

Low, M. B., \& MacMillan, I. C. (1988). Entrepreneurship: Past Research and Future Challenges. Journal of Management, 14(2), 139-161. https://doi.org/10.1177/014920638801400202

Lundvall, B. Å. (1992). National innovation Systems: towards a Theory of Innovation and Interactive learning. Pinter Publishers, London.

Marr, B. (2005). The evolution and convergence of Intellectual Capital as a theme. In Marr, B. (Ed.), Perspectives on Intellectual Capital. Elsevier, Burlington, MA.

Marr, B. (2006). Strategic Performance Management - Leveraging and measuring your intangible value drivers. Butterworth-Heinemann, Elsevier Ltd., Burlington, MA.

Marr, B., \& Roos, G. (2005). A strategy perspective on intellectual capital. In Marr, B. (Ed.), Perspectives on Intellectual Capital. Elsevier, Burlington, MA.

Martínez-Román, J. A., Gamero, J., \& Tamayo, J. A. (2011). Analysis of innovation in SMEs using an innovative capability-based non-linear model: a study in the province of Seville (Spain). Technovation, 31(9), 459-475. https://doi.org/10.1016/j.technovation.2011.05.005

Marzo, G., \& Scarpino, E. (2016). Exploring intellectual capital management in SMEs: an in-depth Italian case study. Journal of Intellectual Capital, 17(1), 27-51. https://doi.org/10.1108/JIC-09-2015-0075 
Massaro, M., Handley, K., Bagnoli, C., \& Dumay, J. (2016). Knowledge management in small and medium enterprises: A structured literature review. Journal of Knowledge Management, 20(2), 258-291. https://doi.org/10.1108/JKM-08-2015-0320

Mazzucato, M. (2014). The Entrepreneurial State - Debunking Public vs. Private Myths. London: Anthem Press.

Mintzberg, H. (1978). Patterns in strategy formation. Management Science, 24(9), 934-948. https://doi.org/10.1287/mnsc.24.9.934

Morris, M. H., Lewis, P. S., \& Sexton, D. L. (1994). Reconceptualizing Entrepreneurship: An Input-Output Perspective. SAM Advanced Management Journal, 59(1), 21-31.

Nabitz, U., Klazinga, N., \& Walburg, J. (2000). The EFQM excellence model: European and Dutch experiences with EFQM approach in health care. International Journal for Quality in Health Care, 12(3), 191-201. https://doi.org/10.1093/intqhe/12.3.191

Neely, A., Filippini, R., Forza, C., Vinelli, A., \& Hii, J. (2001). A framework for analysing business performance, firm innovation and related contextual factors: perceptions of managers and policy makers in two European regions. Integrated Manufacturing Systems, 12(2), 114-124. https://doi.org/10.1108/09576060110384307

Nelson, R. R. (1994). Routines. In G. Hodgson, W. Samuels and M. Tool (Eds.), The Elgar Companion to Institutional and Evolutionary Economics, 2, 249-253. Edward Elgar, Aldershot.

Nelson, R. R., \& Winter, S. G. (1977). In search of useful theory of innovation. Research Policy, 6(1), 36-76. https://doi.org/10.1016/0048-7333(77)90029-4

Nelson, R. R., \& Winter, S. G. (1982). An Evolutionary Theory of Economic Change. Cambridge: Harvard University Press.

Newberry, S., \& Ram, S. (2013). IFRS for SMEs: the IASB two process. Australian Accounting Review, 13(1), 3-17. https://doi.org/10.1111/j.1835-2561.2012.00174.x

Nielsen, C. (2019). From innovation performance to business performance: Conceptualising a framework and research agenda. Meditari Accountancy Research, 2-16. https://doi.org/10.1108/MEDAR-03-2018-0318

Nixon, B., \& Burns, J. (2012). The paradox of strategic management accounting. Management Accounting Research, 23(4), 229-244. https://doi.org/10.1016/j.mar.2012.09.004

Nonaka, I. (1994). A Dynamic Theory of Organizational Knowledge Creation. Organization Science, 5(1), 14-37. https://doi.org/10.1287/orsc.5.1.14

O'Sullivan, M. (2000). The Innovative Enterprise and Corporate Governance. Cambridge Journal of Economics, 24(4), 393-416. https://doi.org/10.1093/cje/24.4.393

Olsson, A., Wadell, C., Odenrick, P., \& Bergendahl, M. N. (2010). An action learning method for increased innovation capability in organizations. Action Learning: Research \& Practice, 7(2), 167-179. https://doi.org/10.1080/14767333.2010.488328

Pavitt, K. (2003). The Process of Innovation. SPRU Paper nr. 89. The Freeman Centre, University of Sussex, Brighton, UK.

Pettigrew, A. (1979). On Studying Organizational Cultures. Administrative Science Quarterly, 24(4), $570-581$. https://doi.org/0001-839217 9/2404-0570\$00.75

Pirozzi, M. G., \& Ferulano, G. P. (2016). Intellectual Capital and performance measurement in healthcare organizations. Journal of Intellectual Capital, 17(2), 320-350. https://doi.org/10.1108/JIC-07-2015-0063

Polanyi, M. (1967). The Tacit Dimension, Anchor Day Books. New York, NY.

Potito, L. (2016). Il bilancio secondo i principi contabili internazionali IAS/IFRS. Giappichelli G. Editore, Torino.

Pratono, A. H. (2016). Strategic orientation and information technological turbulence: Contingency perspective in SMEs. Business Process Management Journal, 22(2), 368-382. https://doi.org/10.1108/BPMJ-05-2015-0066

Quaglino, G. P. (2010). Scritti di formazione (1989-2009), Vol. 5: Clima e motivazione. Collana Associazione Italiana Formatori, F. Angeli.

Quaglino, G. P., \& Mander, M. (1987). I climi organizzativi. Il Mulino, Bologna. 
Quinn, R. E., \& Cameron, K. (1983). Organizational Life Cycle and Shifting Criteria of Effectiveness: Some Preliminary Evidence. Management Science, 29(1), 33-51. https://doi.org/10.1287/mnsc.29.1.33

Rahman, H., \& Ramos, I. (2011). Is Open innovation imperative to Small and Medium Enterprises?: A comparative study. Proceedings of the Seventeenth Americas Conference on Information Systems, Detroit, Michigan.

Rodriguez Ferradas, M. I., Alfaro Tanco, J. A., \& Sandulli, F. (2017). Relevant factors of innovation contests for SMEs. Business Process Management Journal, 23(6), 1196-1215. https://doi.org/10.1108/BPMJ-10-2016-0201

Roos, G., Bainbridge, A., \& Jacobsen, K. (2001). Intellectual capital analysis as a strategic tool. Strategy and Leadership Journal, 29(4), 21-26. https://doi.org/10.1108/10878570110400116

Roslender, R., \& Hart, J. S. (2010). Strategic Management Accounting: Lots in a Name? Retrieved from https://www.hw.ac.uk/schools/social-sciences/documents/dp2010-aef05.pdf

Rothwell, R. (1994). Towards the Fifth-generation Innovation Process. International Marketing Review, 11(1), 7-31. https://doi.org/10.1108/02651339410057491

Rumelt, R. P. (1984). Toward a strategic theory of the firm. In Lamp, R. B. (Eds.), Competitive Strategic Management. Prentice hall, Englewood Cliffs, NJ.

Sánchez-Cañizares, S. M., Ayuso Muñoz, M. A., \& López-Guzmán, T. (2007). Organizational culture and intellectual capital: a new model. Journal of Intellectual Capital, 8(3), 409-430. https://doi.org/10.1108/14691930710774849

Saunila, M. (2016). Performance measurement approach for innovation capability in SMEs. International Journal of Productivity and Performance Management, 65(2), 162-176. https://doi.org/10.1108/IJPPM-08-2014-0123

Saunila, M., \& Ukko, J. (2013). Facilitating innovation capability through performance measurement: a study of Finnish SMEs. Management Research Review, 36(10), 991-1010. https://doi.org/10.1108/MRR-11-2011-0252

Saunila, M., Ukko, J., \& Rantanen, H. (2014). Does innovation capability really matter for the profitability of SMEs? Knowledge and Process Management, 21(2), 134-142. https://doi.org/10.1002/kpm.1442

Schein, E. H. (1984). Coming to a New Awareness of Organizational Culture. MIT SLOAN Management Review, 25(2),. 3-16

Schein, E. H. (1990). Organizational Culture. American Psychologist, 43, 109-119. https://doi.org/10.1037/0003-066X.45.2.109

Schneider, B., Salvaggio, A. N., \& Subirats, M. (2002). Climate strength: A new direction for climate research. Journal of Applied Psychology, 87(2), 220-229. https://doi.org/10.1037/0021-9010.87.2.220

Schneider, B., White, S., \& Paul, M. C. (1998). Linking service climate and customer perceptions of service quality: Test of a causal model. Journal of Applied Psychology, 83(2), 150-163. https://doi.org/10.1037/0021-9010.83.2.150

Schumpeter, J. A. (1934). The Theory of Economic Development: An Inquiry into Profits, Capital, Credit, Interest, and the Business Cycle. Cambridge, MA: Harvard University Press.

Shane, S., \& Venkataraman, S. (2000). The Promise of Entrepreneurship as a Field of Research. The Academy of Management Review, 25(1), 217-226. https://doi.org/10.2307/259271

Shaw, C. D. (2000). External quality mechanisms for health care: summary of the ExPeRT project on visitatie, accreditation, EFQM and ISO assessment in European Union countries. International Journal for Quality in Health Care, 12(3), 169-175. https://doi.org/10.1093/intqhe/12.3.169

Simmonds, K. (1981). Strategic Management Accounting, Management Accounting (CIMA).

Stam, C. D. (2010).Ideas and things: understanding the dynamic dimension of intellectual capital. European Conference on Intellectual Capital Proceedings, Lisbon, January.

Storey, J., \& Holti, R. (2013). Leadership for the NHS”, NHS - Leadership Academy, London. Retrieved from http://www.leadershipacademy.nhs.uk

Subramaniam, M., \& Youndt, M. A. (2005). The influence of Intellectual Capital on the types of innovative 
capabilities. Academy of Management Journal, 48(3), 450-463. https://doi.org/10.2307/20159670

Trott, P. (2005). Innovation Management and New Product Development (3rd ed.). Harlow, Pearson Education Limited, England.

Tushman, M. L., \& O'Reilly, C. A. (1996). Ambidextrous Organizations: Managing Evolutionary and Revolutionary Change. California Management Review, 38(4), 8-30. https://doi.org/10.2307/41165852

Tushman, M. L., \& O'Reilly, C. A. (1999). Building Ambidextrous Organizations: Forming Your Own "Skunk Works". Health Forum Journal, 42(2), 20-23.

Van der Merwe, N., \& Visser, S. S. (2008). Performance management in the South African motor manufacturing industry: a framework. Meditari Accountancy Research, 16(2), 189-211. https://doi.org/10.1108/10222529200800020

Wernerfelt, B. (1984). A resources-based view of the firm. Strategic Management Journal, 5(2), 148-165. https://doi.org/10.1002/smj.4250050207

West, M. A. (1990). The Social Psychology of Innovation in Groups. In M. A. West and J.L Farr (Eds.), Innovation and Creativity at Work: Psychological and Organizational Strategies. Wiley, Chichester - UK.

West, M. A., \& Anderson, N. R. (1996). Innovation in top management teams. Journal of Applied Psychology, 81(6), 680-693. https://doi.org/10.1037/0021-9010.81.6.680

West, M. A., Smith, H., Feng, W. L., \& Lawthom, R. (1998). Research excellence and departmental climate in British universities. Journal of Occupational and Organizational Psychology, 71(3), 261-281. https://doi.org/10.1111/j.2044-8325.1998.tb00676.x

Whittington, R. (2001). What is Strategy-and Does it Matter? (2nd ed.). Cengage Learning EMEA, Hampshire.

Wiseman, R. W., \& Skilton, P. F. (1999). Divisions and differences: Exploring publication preferences and productivity across management subfields. Journal of Management Inquiry, 8, 299-320. https://doi.org/10.1177/105649269983008

Wright, P. M., Dyer, L., \& Takla, M. G. (1999). Execution: The critical "what's next? in Strategic Human Resource Management. CAHRS Working Paper nr. 11, Cornell University, Ithaca, NY -Retrieved from http://digitalcommons.ilr.cornell.edu/cahrswp/110

Yin, R. (2005). Lo studio di caso nella ricerca scientifica. Armando Editore.

Zhao, F. (2014). A holistic and integrated approach to theorizing strategic alliances of small and medium-sized enterprises. Business Process Management Journal, 20(6), 887-905. https://doi.org/10.1108/BPMJ-01-2013-0004

\section{Copyrights}

Copyright for this article is retained by the author(s), with first publication rights granted to the journal.

This is an open-access article distributed under the terms and conditions of the Creative Commons Attribution license (http://creativecommons.org/licenses/by/4.0/). 